\title{
Sentidos de prática pedagógica na produção brasileira sobre formação inicial de professores de ciências $(2000-2010)^{\prime}$
}

\author{
Priscila Correia Fernandes" \\ Danusa Munford"I' \\ Marcia Serra Ferreiralv
}

\footnotetext{
I-Texto produzido no âmbito da pesquisa Sentidos das relações entre teoria e prática em cursos de formação de professores em Ciências Biológicas: entre histórias e políticas de currículo, com financiamento do CNPq e da FAPERJ.

II- Universidade Federal de São João del-Rei, São João del-Rei, MG, Brasil. Contato: priscila@ufsj.edu.br

III- Universidade Federal de Minas Gerais, Belo Horizonte, MG, Brasil. Contato: danusamun@gmail.com IV- Universidade Federal do Rio de Janeiro, Rio de Janeiro, RJ, Brasil. Contato: marciaserra.f@gmail.com
}

\begin{abstract}
Resumo
No presente trabalho, pretendemos propor um quadro analítico para caracterizar os sentidos de prática construídos no campo de pesquisa da formação de professores, a partir da análise da produção sobre formação de professores de ciências no Brasil. Nossa investigação ancora-se na perspectiva de que o contexto da pesquisa científica sobre formação de professores constrói significados, os quais são reproduzidos e ressignificados nos cotidianos escolares, nos percursos formativos de professores de ciências e licenciandos, nas concepções de sucesso e fracasso da escola. Nosso trabalho, portanto, tem o potencial de contribuir para compreendermos como são estruturadas visões sobre o professor em formação e sobre sua prática. A partir dos modelos de ação propostos por Jürgen Habermas, desenvolvemos uma análise de como o objeto de estudo prática pedagógica é construído nos textos de artigos publicados em periódicos nacionais Qualis A de educação em ciências no período de 2000-2010. Os resultados de nossas análises indicam que há uma tendência a compreender a prática como ação estratégica direcionada ao mundo dos objetos escolares, seus métodos e seus materiais. A prática como ação comunicativa, a qual se direciona à escola como pertencente, simultaneamente, aos mundos objetivo, dramático e das normas, é sensivelmente presente nos devires da prática pedagógica.
\end{abstract}

\section{Palavras-chave}

Formação de professores - Prática pedagógica - Categorias de ação. 


\title{
Meanings of the pedagogical practice in the Brazilian production on the initial education of science teachers (2000-2010)'
}

\author{
Priscila Correia Fernandes" \\ Danusa Munford"II \\ Marcia Serra Ferreiralv
}

I- Text produced within the research Sentidos das relações entre teoria e prática em cursos de formação de professores em Ciências Biológicas: entre histórias e políticas de currículo (Meanings of the relations between theory and practice in teacher education courses in Biological Sciences: between curriculum history and policy), funded by $\mathrm{CNPq}$ and FAPERJ.

II- Universidade Federal de São João del-Rei, São João del-Rei, MG, Brasil.

Contact: priscila@ufsj.edu.br

III- Universidade Federal de Minas Gerais, Belo Horizonte, MG, Brasil.

Contact: danusamun@gmail.com

IV- Universidade Federal do Rio de Janeiro

UFRJ, Rio de Janeiro, RJ, Brasil.

Contact: marciaserra.f@gmail.com

\begin{abstract}
In this work, we propose an analytical framework to characterize the meanings of practice constructed in teacher education research, analyzing the production in science teacher education in Brazil. Our research is founded on the perspective that the context of scientific research on teacher education constructs meanings, which are reproduced and reinterpreted in school everyday, in the training pathways of science teachers and undergraduates, in the notions of success and failure in schools. Therefore, our work has the potential to contribute to understanding how views about teachers in training and about their practice are structured. Using the models of action proposed by Jürgen Habermas, we develop an analysis of how the object of study pedagogical practice is constructed in the articles published in national Qualis A journals of science education in the period 2000-2010. The results of our analyzes indicate that there is a tendency to understand practice as a strategic action aimed at the world of school objects, its methods and materials. Practice as communicative action, which aims at the school as belonging simultaneously to the objective, dramatic world and to the world of standards, is substantially present in the becomings of the educational practice.
\end{abstract}

\section{Keywords}

Teacher education - Educational practice - Categories of action. 


\section{Sobre a formação de professores}

A formação de professores é recorrentemente anunciada como um processo fundamental para a melhoria da qualidade da educação. Remete à necessidade de formar mais e melhor os professores, em uma explícita responsabilização desses profissionais pela situação da educação (CALDAS, 2007; CARVALHO, 2001). São também responsabilizadas as instituições de formação de professores, em discursos apoiados na necessidade da reforma, emergidos dos documentos e das políticas públicas voltadas à educação. Em meio a um aparente consenso sobre a necessária reforma na formação de professores, surgem questões como: Quais discursos de formação de professores estão em jogo atualmente no Brasil e quais efeitos de poder esses discursos fazem emergir? Que instituições são responsabilizadas a agir e quais são os resultados dessas ações? A falta de professores em exercício relaciona-se exclusivamente a um déficit no número de professores sendo formados? Quais outros processos compõem a estrutura de ideias da falta qualitativa e quantitativa de professores para a educação básica?

A discussão que apresentamos procura trazer à tona alguns desses aspectos da formação de professores, na busca por uma melhor compreensão de processos ainda pouco desenvolvidos pela pesquisa atual no campo. Buscamos apoio teórico para nossa pesquisa no livro de Thomas Popkewitz (2001), situado no contexto do programa estadunidense de formação de professores Teach for America. De acordo com o autor, o trabalho não é sobre o programa, mas sim "um esforço para compreender como diferentes discursos da pedagogia unem-se para gerar princípios à participação e à ação" (POPKEWITZ 2001, p. 14). Essa estrutura de ideias está subordinada a um sistema de raciocínio no contexto da formação de professores:

Uma suposição que está por trás de grande parte do discurso contemporâneo sobre ensino é que há caminhos racionais para a salvação - a escola eficaz, o professor eficiente e autêntico [...]. Porém, quando examinamos as práticas de formulação de políticas e de pesquisa, não encontramos segurança moral, política e cultural. [...] Este estudo sugere que as ideias inserem projetos políticos e que um dos papeis das práticas intelectuais é questionar o dogma reinante sobre o significado intelectual dos atores e as regras do processo. (POPKEWITZ 2001, p. 15)

Portanto, as práticas de formação de professores não ocorrem em um vácuo; elas situam-se em um sistema de raciocínio. Essa estrutura é formada por discursos que, por defınição, são polissêmicos, polifônicos, muitas vezes autoritários. Os discursos que compõem as estruturas dos sistemas de ideias são efeitos de poder que produzem significados sobre o que é o fracasso, o desejável, o necessário. Assim, o trabalho de Popkewitz (2001) contribui no sentido de propor construtos para estudarmos os significados construídos nos discursos aparentemente hegemônicos. Ele faz um endereçamento explícito do livro "para professores que procuram investigar criticamente os sistemas de raciocínio que organizam o seu ensino" (POPKEWITZ 2001, p. 14). Esse referencial justifica nossa investigação acerca dos sistemas de raciocínio sobre as práticas pedagógicas que emergem dos textos das pesquisas no campo de formação de professores de ciências. Nosso objetivo é, a partir do uso de categorias alternativas de análise, discutir como noções de prática pedagógica são construídas nesse campo.

\section{A prática como formadora de professores}

Um primeiro movimento para investigarmos sistemas de raciocínio seria reconhecer os sentidos que circulam nas pesquisas acadêmicas a respeito da formação de professores. A recente literatura sobre saberes docentes 
enfatiza o saber fazer e privilegia o conhecimento construído na experiência da docência (FEITOSA; LEITE; FREITAS, 2011; FREITAS, 2002; TARDIF, 2006; TERRIEN, 1997). Para Donald Schön (1998), a prática pedagógica é um momento de construção de conhecimento por meio da reflexão na ação e sobre a ação; dessa forma, segundo o autor, a prática pedagógica é a atividade fundamental para a formação docente. Tal perspectiva também está presente em trabalhos de autores do campo de ensino de ciências (BEJARANO; CARVALHO, 2003; ECHEVERRÍA; BELISÁRIO, 2008; ROSA et al., 2003; ROSA; MEDEIROS; SHIMABUKURO, 2001). Além disso, há uma influência da epistemologia da prática nas avaliações sobre a qualidade docente (FRANCO et al., 2007; ROCHA; PEROSA, 2008; SZTAJN; BONAMINO; FRANCO, 2003). É evidente a ênfase dada aos saberes da prática como construtos da formação docente nas reformas curriculares propostas pelo MEC, explicitadas pelo Parecer CNE 009/2001 e pela Resolução CNE/CP 001 de 2002, culminando na prática como componente curricular (CARVALHO, 2001; NUNES, 2001). Contudo, um trabalho mais sistematizado é necessário para caracterizar os sistemas de raciocínio que têm orientado as práticas pedagógicas no contexto de formação. Assumimos que "a prática não é externa à teoria, é sim um conceito teórico que 'conta' a alguém como o mundo deve ser agregado e pensado" (POPKEWITZ, 2001, p. 88).

\section{Perspectivas da pesquisa}

Para Zeichner (2011), os pesquisadores têm identificado, recorrentemente, problemas persistentes na formação de professores, que não têm sido abordados de forma significativa pelas pesquisas, mesmo com toda a produção dos últimos 30 anos. No Brasil, vários autores têm se dedicado a mapear aspectos do campo (ANDRÉ et al., 1999; BERZEZINSKI, 2006; GATTI, 2002). Encontramos discussões consistentes sobre modelos de formação de professores, seus paradigmas e suas fundamentações (DINIZ-PEREIRA,
2007; SANTOS, 2007), bem como muitos trabalhos desenvolvidos na perspectiva dos saberes docentes (NUNES, 2001; TARDIF, 2006).

Entretanto, há vários aspectos pouco explorados em pesquisas do estado da arte, considerando-se o contexto social dessa produção acadêmica. Não é raro pesquisadores aproximarem-se do texto escrito - neste caso, artigos, dissertações e teses - de forma diferente daquelas que são comuns na análise de textos orais. Aspectos da análise do discurso, como a dimensão social e institucional dos textos, muitas vezes, não são incorporados na análise dos textos escritos (BAZERMAN; PRIOR, 2004). Assim, segundo esses autores, muitas vezes, ficamos restritos a uma tendência a identificar $o$ que os textos significam, em vez de olharmos para como os textos significam. Uma imagem apresentada pelos mesmos autores em outro trabalho (BAZERMAN; PRIOR, 2005, p. 137) ilustra bem o que essa nova abordagem implicaria:

0 texto unidimensional, quando interagindo com a imaginação e a compreensão do leitor ou do escritor, tem de servir como um tipo de placa holográfica: ele tem de ser ativamente iluminado para projetar uma imagem tridimensional de um mundo social - um com autores, leitores, motivos sociais e objetos de referência. As palavras, símbolos e espaços mortos devem, de alguma forma, tornar-se vivas para animar relações, situações comunicativas e mensagens significativas.

Para investigar os sistemas de raciocínio materializados nos textos sobre formação de professores de ciências, assumimos como referência a teoria social de Jürgen Habermas, por vermos nessa fundamentação uma contribuição significativa para a análise dos textos das pesquisas.

Para a pesquisa de abordagem sócio-histórica (WERTSCH, 1993), o foco nas ações e nas interações justifica-se por serem elas as únicas categorias analíticas que participam do jogo de 
significações contextuais. 0 mesmo autor ressalta a polissemia nos sentidos de $a c ̧ a ̃ o$ e os investiga com base nos trabalhos de Jürgen Habermas:

Dizer que uma abordagem incorpora uma noção de ação como ponto de partida, entretanto, ainda deixa uma questão importante em aberto. Muitos tipos de ação podem ser identificados e, portanto, é essencial que se especifique o tipo ou tipos de ação que se tem em mente. (WERTSCH, 1993, p. 11, tradução nossa)

Habermas definiu um conjunto de categorias de ação baseado nas relações entre ator e objeto. Assim, orientado pela relação ator-ambiente em uma perspectiva sociológica, ele se volta para a concepção dos três mundos de Karl Popper, a saber: i) o mundo dos objetos ou estados físicos; ii) o mundo dos estados de consciência, estados mentais ou disposições comportamentais à ação; e iii) o mundo dos conteúdos do pensamento, especialmente os pensamentos científicos e poéticos. Com base nesses conceitos de mundo, Habermas concebe uma tipologia geral da ação, categorizando-a em: i) ação teleológica ou estratégica; ii) ação dramatúrgica; iii) ação normativa; e iv) ação comunicativa.

Considerando a relação do ator com o mundo dos objetos físicos, Habermas concebe o conceito de ação estratégica, segundo a qual

o ator alcança um fim ou produz a ocorrência de um estado desejado, escolhendo meios com potencial de sucesso na situação dada e os aplicando de uma maneira adequada. 0 conceito central é o de uma decisão entre caminhos alternativos de ação, com vistas à concretização de um fim, guiados por máximas e com base em uma interpretação da situação. (1984, p.85, tradução nossa).

No contexto da prática pedagógica na formação de professores de ciências, o modelo de ação estratégica envolveria a busca por desenvolver meios adequados - nesse caso, abordagens, estratégias, métodos, técnicas de ensino, sequências didáticas - para se atingir uma finalidade, como promover a aprendizagem de ciências entre estudantes da educação básica. 0 ator - o professor - age sobre o objeto - aulas - para obter dado resultado, sendo sua avaliação pautada na eficácia das escolhas e na utilização das estratégias. Habermas afirma que:

os sujeitos que agem estrategicamente precisam ser equipados cognitivamente para agir com os objetos físicos, bem como para que os sistemas de tomada de decisão possam aparecer no mundo. Eles precisam ampliar seu aparato conceitual para o que pode ser o caso; mas eles não necessitam de pressupostos ontológicos mais ricos. (1984, p. 88, tradução nossa)

0 segundo modelo de ação relaciona o ator ao mundo dos estados de consciência ou das disposições de comportamento, de Popper. Habermas (1984, p. 86, tradução nossa) o define como uma ação dramatúrgica na qual "o ator evoca em seu público uma certa imagem e impressão de si mesmo". Em tal modelo de ação, o ator se apresenta de forma estilizada com objetivos estratégicos. Nesse caso, o importante são os conceitos de sinceridade, autenticidade e verdade. No contexto da formação de professores, esse modelo vê na prática docente o exercício de sentir-se professor nas experiências afetivas com os alunos, com o ambiente de trabalho e com os colegas, sejam eles agradáveis ou não. 0 modelo dramatúrgico também se expressa na prática da docência como atividade de formação, ao enfatizar a experiência da realidade da escola. Tal realidade configura--se nos sentimentos próprios da atividade profissional, no comportar-se como professor, no caráter subjetivo da docência. Esse modelo centra-se na construção da identidade do professor, tida como construção subjetiva de sentimentos e competências próprias do ser professor. A reflexão é a tomada 
de consciência sobre os processos ocultos da prática, a identificação das práticas naturais, das concepções naïve da atividade docente e o processo de internalização de crenças e atitudes próprias da docência.

0 terceiro modelo de ação expressa a relação entre o ator e o mundo do pensamento, que produz a ação normativa. Nesse caso, a ação não está circunscrita à individualidade do ator em relação ao mundo objetivo ou a um ambiente, mas se materializa na relação com os membros de um grupo que orientam suas ações a um conjunto de valores:

Assim, o ator individual age em conformidade ou viola uma norma em uma dada situação. As normas expressam um acordo em um grupo social... 0 conceito central é o cumprimento de uma expectativa generalizada de comportamento. (WERTSCH, 1993, p. 11, tradução nossa)

No modelo normativo, o ator, professor em formação, dirige suas atividades práticas às normas do ambiente profissional, à escola com ênfase no papel social do professor, no engajamento em atividades práticas da profissão e da profıssionalização. 0 modelo é permeado também pelas concepções de comunidade de prática e pelas regras que a estabelecem, relacionadas ao conceito de construção de identidade social.

0 quarto modelo de ação proposto por Habermas não está diretamente ligado aos três conceitos de mundo propostos por Popper. Ele nomeou esse quarto modelo de ação comunicativa, a qual se refere à interação de pelo menos dois sujeitos que são capazes de discursar e argumentar e que, portanto, estabelecem relações interpessoais (por meios verbais ou extra-verbais). Os atores negociam as ações e pretendem chegar a um consenso sobre aquela ação:

0 conceito central de interpretação, em primeira instância, refere-se a negociar definições da situação que admite consen- so. Como veremos, a linguagem tem lugar proeminente nesse modelo. [...] Porque a validade de afırmações pode ser criticada, há a possibilidade de se identificarem e se corrigirem erros, ou seja, aprender-se a partir deles. Se isso for levado a termo em um nível reflexivo, modos de argumentação tomam formas, as quais podem ser transmitidas e desenvolvidas dentro de uma tradição cultural e até incorporadas em instituições culturais específicas. (HABERMAS, 1984 p. 86, tradução nossa)

Baseados nas finalidades das ações propostas por Habermas, buscamos caracterizar, em artigos publicados no Brasil, as noções de prática pedagógica na formação inicial de professores.

\section{A constituição do corpus de análise}

Para constituição do corpus, inicialmente partimos de um mapa traçado no grupo a respeito da recente produção brasileira sobre o tema da formação inicial e continuada de professores no ensino de disciplinas escolares em ciências, no período de 2000 a 2010, em quatro periódicos nacionais (CASARIEGO; LUCAS; FERREIRA, 2011). Os periódicos analisados são apresentados no quadro 1.

Nossa seleção de artigos envolveu uma busca em resumos, títulos e palavraschave pelos seguintes termos: formação de professores, formação inicial de professores, formação de professores de ciências. Em seguida, foi realizada uma leitura dos resumos e foram descartados artigos que não tinham como foco principal a formação inicial de professores. Após essa etapa, efetuamos uma busca automática pelos termos prática e estágio nos textos completos e 38 artigos foram selecionados. Então, após a leitura desses textos pré-selecionados, excluímos das análises artigos que contemplavam contextos de pesquisa que se distanciavam de nosso 
Quadro 1 - Relação de periódicos pesquisados

\begin{tabular}{l|ccc}
\multicolumn{1}{c}{ Nome } & \multicolumn{1}{c}{ Descrição } & $\begin{array}{c}\text { Início de } \\
\text { publicação }\end{array}$ \\
\hline \multirow{2}{*}{ Ciência e Educação } & Editado pelo Programa de Pós-Graduação em Educação para a Ciência, da & 1995 \\
& Faculdade de Ciências da UNESP-Bauru. & $\vdots$ \\
\hline \multirow{3}{*}{ Ensaio: Pesquisa em Educação em Ciências } & Programa de Pós-Graduação em Educação da Faculdade de Educação da & 1999 \\
& UFMG. & $\vdots$ \\
\hline \multirow{2}{*}{ Investigações em Ensino de Ciências } & Editado pelo Instituto de Física da UFRGS. & 1996 \\
\hline Revista Brasileira de Pesquisa em Educação \\
em Ciências (RBPEC) & Editado pela Associação Brasileira de Pesquisa em Educação em Ciências & $\vdots$ & 2001 \\
& (ABRAPEC). & $\vdots$ \\
\hline
\end{tabular}

objeto de análise. Assim, foram finalmente selecionados 29 artigos que constituíram o corpus de análise para o presente trabalho. 0s artigos analisados estão listados ao final das referências bibliográficas. Mais fortemente interessadas nos sentidos de prática pedagógica - e não nas autorias -, optamos por atribuir a esses artigos números de 1 a 29 . Ao apresentarmos os resultados, as citações seguem, portanto, essa referência numérica.

\section{Processo analítico e elaboração de categorias}

Durante a análise, foi especialmente útil a exploração das justificativas, dos objetivos e da avaliação do desenvolvimento de atividades na escola. Muitas vezes, esses objetivos foram evidenciados na introdução do texto, em que os autores explicitam seus referenciais teóricos. Buscamos, entretanto, analisar todo o texto, por encontrarmos muitas evidências de concepções sobre a prática pedagógica durante as discussões e conclusões adicionais àquelas eleitas como relevantes nos referenciais teóricos das introduções dos artigos.

Para esse trabalho, fizemos pelo menos três leituras dos artigos completos. Na primeira, criamos códigos relacionados a como as práticas são concebidas no texto como um todo. Na segunda, observamos quais categorias de ação estão sendo evocadas a cada re- ferência a essas práticas. Na terceira, fizemos uma checagem dessas categorias e buscamos informações adicionais, principalmente quanto à bibliografia citada pelos autores, às relações estabelecidas pelas práticas categorizadas como diferentes e ao processo de desenvolvimento da pesquisa. Ao longo das leituras, foi possivel identificar pistas que nos levaram a identificar as ideias de prática dos textos e nos indicaram uma aproximação à categoria proposta, possibilitando a categorização. No quadro 2, apresentamos exemplos de como foi realizada a categorização. Aspectos mais importantes dos textos no processo de categorização são destacados em negrito.

A partir dessa categorização, desenvolvemos três dimensões para a análise. A primeira refere-se à compreensão da prática como ação estratégica na formação de professores. A segunda investiga a apropriação da literatura no campo da educação em ciências, em sua relação com as práticas pedagógicas. A terceira investiga as relações entre as ações e os contextos elaborados pelas pesquisas. Ao analisarmos as dimensões enfatizadas pelos textos, identificamos os sujeitos das pesquisas, os métodos de coleta de dados e os resultados apresentados. Elaboramos, então, categorias de dimensões de pesquisa, partindo dos níveis de análise individual, do grupo ou geral. Também demarcamos a ênfase explicitada pelos textos como macrocontextuais ou microcontextuais. 
Quadro 2 - Modelo de construção e atribuição de categorias de ação aos trabalhos analisados

\begin{tabular}{|c|c|c|}
\hline Categoria & Aspectos-chave & Exemplos (grifos nossos) \\
\hline Estratégica & $\begin{array}{l}\text { Busca um modelo a ser seguido; } \\
\text { processo determinado previamente } \\
\text { com o objetivo de melhoria do } \\
\text { sistema; prática utilitária; produção de } \\
\text { objeto, método ou receita; suposição } \\
\text { de um modelo ideal a ser alcançado. } \\
\text { Prática como atividade a ser } \\
\text { desenvolvida, refletida teoricamente } \\
\text { e melhorada. Ideia de processo } \\
\text { e finalidade objetiva. A prática } \\
\text { pedagógica como a própria aula. }\end{array}$ & $\begin{array}{l}\text { "A observação é parte do processo metodológico. A reflexão é o momento } \\
\text { em que, baseados nos dados da observação, ponderamos e avaliamos o } \\
\text { que ocorreu na ação, de acordo com o que foi feito no planejamento, e mais, } \\
\text { apontamos esse novo conhecimento produzido. Em cada ciclo da espiral, a } \\
\text { ação prática se fortalece e a prática vai sendo cada vez mais aperfeiçoada. Os } \\
\text { participantes tornam-se mais conhecedores do processo e, principalmente, de } \\
\text { suas próprias práticas." (12) } \\
\text { "Nesse período houve um incessante esforço do grupo no sentido de garantir } \\
\text { um movimento de ideias e ações para a melhora da prática pedagógica." (21) }\end{array}$ \\
\hline Dramatúrgica & $\begin{array}{l}\text { Referência psicanalítica; tornar-se } \\
\text { professor; sentimentos atribuídos à } \\
\text { atividade docente. }\end{array}$ & $\begin{array}{l}\text { "0 trabalho enfatiza que a experiência de prática de ensino, o planejamento e } \\
\text { demais atividades foram importantes para a formação de um grupo de docentes } \\
\text { comprometidos com as tarefas do ensino. Mudaram disposições internas de } \\
\text { comportamento, mudou o comprometimento." (2) } \\
\text { "A análise e interpretação será conduzida a partir de um referencial psicanalítico, } \\
\text { privilegiando as modificações no saber e na satisfação dos sujeitos envolvidos." (1) }\end{array}$ \\
\hline Normativa & $\begin{array}{l}\text { Relação à profissão docente; ênfase } \\
\text { nos contextos sociais da escola e da } \\
\text { profissão docente; comprometimento } \\
\text { ideológico. }\end{array}$ & $\begin{array}{l}\text { "Se entendermos que a educação básica tem como meta central a formação } \\
\text { de jovens brasileiros para o exercício consciente da cidadania, precisamos } \\
\text { compreender o papel do ensino de Química no processo de formação de } \\
\text { cidadania e assumir esse desafio, na busca de processos de formação de } \\
\text { professores nos quais eles possam desenvolver atitudes e valores, por meio da } \\
\text { interatividade em sala de aula." (7) } \\
\text { "0 contexto da escola, suas características e normas de funcionamento } \\
\text { também foram elementos que permearam diversos momentos das discussões, } \\
\text { especialmente nas ocasiões de análise das aulas, quando assistiam às } \\
\text { gravações das atividades." (14) }\end{array}$ \\
\hline Comunicativa & $\begin{array}{l}\text { Aproximação comunicativa dos vários } \\
\text { atores envolvidos na formação, nos } \\
\text { contextos da escola e da universidade; } \\
\text { ênfase no diálogo de saberes, } \\
\text { tutoria e mentoria; ideal e devir; } \\
\text { ênfase na literatura sócio-histórica e } \\
\text { fundamentação nos discursos. }\end{array}$ & $\begin{array}{l}\text { "Se nossa leitura for correta, o problema de formar os futuros professores para } \\
\text { uma competência científica, didática e dialógica pode ser entendido, no caso da } \\
\text { Prática de Ensino, como o de favorecer que cada grupo de futuros professores } \\
\text { consiga desenvolver seu trabalho até escolher um determinado mote que } \\
\text { forneça um rumo no interior de mudanças externas e internas, na ação e no } \\
\text { saber implícito, extremamente complexas. Estabelecer um mote constituiria } \\
\text { o caminho para o grupo de licenciandos alcançar uma relativa autonomia e } \\
\text { experimentar um diálogo efetivo com seus professores." (2) }\end{array}$ \\
\hline
\end{tabular}

\section{Processo de construção de significados}

A construção analítica desenvolvida está resumida no quadro 3. A maior parte dos estudos analisados refere-se à formação do professor reflexivo. Suas bases teóricas normalmente estão relacionadas com os trabalhos de Schön, Zeichner, Nóvoa e seus respectivos grupos. Parece haver certa hegemonia acerca da necessidade de formar um professor que reflete sobre a prática pedagógica, embora muitos textos também reconheçam criticamente limitações da formação reflexiva.

Dos trabalhos analisados, a grande maioria refere-se à prática pedagógica com componentes de ação estratégica. Também há uma predominância de foco das pesquisas em grupos de alunos de licenciatura, professores em formação continuada e professores formadores. 
Os contextos de pesquisa enfatizados também foram observados. Os dados analisados estão descritos no quadro 3.

Quadro 3 - Descrição da análise dos artigos quanto à categoria de ação e à dimensão de pesquisa enfatizada

\begin{tabular}{|c|c|c|c|c|}
\hline \multirow{2}{*}{ Artigo } & \multicolumn{3}{|c|}{ Ação/Prática } & \multirow{2}{*}{ Contexto/Dimensão } \\
\hline & $\mathrm{T}$ & D $N$ & C & \\
\hline 1 & & & & Micro - Indivíduo \\
\hline 2 & & $\vdots$ & & Micro - Indivíduo \\
\hline 3 & & $\vdots$ & & Macro - Grupo \\
\hline 4 & & $\vdots$ & & Macro - Licenciatura \\
\hline 5 & & $\vdots$ & & Macro - Grupo/Objeto \\
\hline 6 & & $\vdots$ & & Macro - Formação de professores \\
\hline 7 & & $\vdots$ & & Micro - Indivíduo \\
\hline 8 & & $\vdots$ & & Micro - Indivíduo \\
\hline 9 & & $\vdots$ & & Macro - Formação de professores \\
\hline 10 & & $\vdots$ & & Macro - Grupo/Geral \\
\hline 11 & & $\vdots$ & & Macro - Grupo \\
\hline 12 & & $\vdots$ & & Macro - Grupo \\
\hline 13 & & $\vdots$ & & Macro - Grupo \\
\hline 14 & & $\vdots$ & & Micro - Indivíduo \\
\hline 15 & & $\vdots$ & & Micro - Indivíduo \\
\hline 16 & & $\vdots$ & & Macro - Grupo \\
\hline 17 & & $\vdots$ & & Macro - Grupo/Geral \\
\hline 18 & & $\vdots$ & & Macro - Grupo/Geral \\
\hline 19 & & 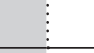 & & Macro - Grupo/Individuo \\
\hline 20 & & $\vdots$ & & Macro - Grupo/Individuo \\
\hline 21 & & : & & Macro - Grupo \\
\hline 22 & & ¿ & & Macro - Grupo \\
\hline 23 & & $\vdots$ & & Macro - Grupo \\
\hline 24 & & $\vdots$ & & Macro - Dimensão geral \\
\hline 25 & & $\vdots$ & & Macro - Geral \\
\hline 26 & & & & Micro - Indivíduo \\
\hline 27 & & & & Macro - Grupo \\
\hline 28 & & 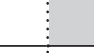 & & Macro - Grupo/Geral \\
\hline 29 & & & & Macro - Grupo \\
\hline
\end{tabular}

Apesar da predominância do caráter estratégico na grande maioria dos trabalhos analisados, a prática pedagógica também foi apresentada como uma ação dirigida às normas e aos desejos, estruturas de raciocínio que constroem um caráter da escola pertencente ao nível subjetivo dos sentimentos e ao nível das normas sociais. Não houve grande diferença em número de citações entre esses dois modelos. Outro aspecto importante é que muitas das referências aos modelos dramatúrgico e normativo aparecem conjuntamente nos mesmos trabalhos. Isso evidencia certa tendência, por parte de alguns autores, de explorar noções de prática pedagógica mais amplas, não circunscritas ao mundo objetivo das estratégias de ensino. Na verdade, em muitos dos trabalhos analisados, mais de uma categoria de ação foi evocada como parte da prática. Essa tendência evidencia a polissemia e heterogeneidade do termo. Tal coexistência reflete-se nos resultados: 13 artigos se referiram a mais de uma categoria de ação, sendo que, nos 29 artigos analisados, obtivemos 42 categorizações de ação. Os contextos enfatizados pelas pesquisas, assim como as dimensões dadas às práticas pedagógicas, também foram analisadas. Esses aspectos são explorados em detalhe ao longo do texto, assim como o caráter de devir das práticas pedagógicas como modelos de ação comunicativa.

\section{Características e distinçōes das práticas estratégicas}

Como já apresentado, há uma grande ênfase em considerar a prática pedagógica no contexto de formação de professores como uma ação estratégica. A prática reflexiva em uma perspectiva de prática estratégica corresponde a ajustar as ações de forma a encontrar a eficiência desejada. Termos como saber-fazer, referenciados em Schön, muitas vezes se ancoram nesse modelo de prática baseada na ação estratégica.

Nesse contexto, há também uma grande variedade de aspectos abordados pela prática pedagógica estratégica. Muitos trabalhos têm enfatizado a necessidade de a prática equipar o professor de conhecimentos pedagógicos de conteúdo (PCK), e há nesse contexto uma 
grande identidade de pesquisadores do campo com os saberes docentes. Um exemplo da relação entre a ação estratégica e a atividade prática para proporcionar oportunidade de aquisição/construção de saberes docentes pode ser encontrado em um trecho do artigo 21:

[as práticas] constituiram-se num instrumento variado e até sofisticado que procurava estabelecer uma comunicação com os licenciandos sobre os elementos que caracterizam a prática de um professor, tais como os critérios de planejamento, condução, sustentação e avaliação do processo de aprendizagem, ou seja, os saberes docentes. (21)

De acordo com nossa análise, identificamos que o campo de pesquisa em educação em ciências dá significativa ênfase a saberes tácitos como reafirmação de que os conhecimentos do professor têm caráter objetivo. É recorrente nas obras analisadas a ideia de que há um mundo objetivo - a escola - onde o professor deverá atuar estrategicamente. Esse reforço não nega a necessidade de consideração do mundo das relações (normas) e das subjetividades (drama), visto que muitos autores têm se referido a esses aspectos da prática além das estratégias, mas enfatizam que os objetos são, sim, importantes.

Em nossas análises, foi possível identificar quais seriam esses objetos do mundo da escola que foram enfatizados nos trabalhos, como: i) o conteúdo; ii) os métodos e as técnicas de ensino-aprendizagem; e iii) os materiais instrucionais.

Alguns trabalhos referiram-se à importância, no campo da educação em ciências, da atenção ao conteúdo de referência nas práticas pedagógicas. São mencionados aspectos como aprofundamento dos conhecimentos e rigor científico aplicado ao conteúdo, ao conhecimento das diretrizes curriculares das escolas e à adequação desse conteúdo às realidades da escola. Um trecho do artigo 25 ilustra como o rigor conceitual é valorizado:
Paralelamente aos estudos de reflexão sobre os textos acima, os licenciandos foram divididos em cinco grupos, com a finalidade de estudar conteúdos de Física (Mecânica, Termologia, Óptica, Eletricidade e Magnetismo e Física Moderna e Contemporânea) que poderiam ser abordados em situações de sala de aula, durante as atividades do estágio de regência no Ensino Médio. (25)

Paralelamente, o seguinte trecho do artigo 3 ilustra a importância que alguns autores atribuem ao conteúdo no contexto da escola:

\section{[...] dificuldade em transformar o saber de referência em saber escolar, fenômeno entendido neste trabalho como mediação didática. (3)}

Além do conteúdo, os métodos de ensino também foram identificados como objetos em relação aos quais as ações dirigiram-se quando os artigos falam de prática.

Pudemos encontrar alguns exemplos de ênfase nesses métodos de ensino sobre os quais os professores em formação deveriam agir estrategicamente, como neste trecho do artigo 5:

Prática de Ensino é o espaço curricular apropriado para o desenvolvimento da prática pedagógica e da consecução da sintese, do estabelecimento de relações e da aplicação dos conhecimentos ao longo do curso. Esta disciplina visa contribuir para a formação de professores no que se refere ao desenvolvimento das competências, tais como: trabalhar em grupo, criar, planejar, realizar e avaliar ações pedagógicas; dominar os conceitos da disciplina a serem ensinados; manejar diferentes estratégias e recursos de comunicação dos conteúdos, sabendo eleger as mais adequadas considerando a 
diversidade dos alunos, os objetivos das atividades propostas e as caracteristicas dos próprios conteúdos, entre outros. (5)

Popkewitz (2001) chama os métodos e as técnicas de ensino - vistos como tecnologias - de conhecimento da receita. Para ele, esse conhecimento "parece definir o que é necessário para os propósitos pragmáticos presentes e futuros nas escolas, fazendo uma separação entre teoria e prática" (p. 88). Além disso, tais conhecimentos "reformularam as questões sociais em procedimentos universais através dos quais os professores iniciantes aprenderam a ser profissionais experientes" (p. 91).

A elaboração de materiais didáticos, seja para utilização em sala de aula, seja para melhoria dos processos de formação docente, também foi apontada como objeto de estratégia nas práticas pedagógicas. Podemos evidenciar esse componente nos excertos selecionados a seguir. 0 trecho do artigo 27 refere-se a um instrumento produzido para evidenciar aspectos relevantes da prática pedagógica no ensino superior:

A elaboração desse instrumento expõe amplamente o docente: obriga-o a um envolvimento pessoal na produção regular dos textos e a um esforço intelectual contínuo para localizar os eventos mais significativos, interpretar seus possiveis sentidos e intervir de maneira adequada, quando possivel. (27)

0 trecho do artigo 11 refere-se à produção de material didático destinado à melhoria do ensino:

Neste semestre as professoras planejavam propor a realização dos estágios em forma de mini-cursos, a serem ministrados em salas de aula na rede Pública de Ensino, com uma frequência de aproximadamente 4 horas por semana (créditos da disciplina destinados ao estágio). (11)

\section{Relação entre referenciais da formação de professores e as categorias de ação}

A segunda dimensão de análise do presente trabalho é a relação entre o referencial teórico citado pelos trabalhos e as categorias de ação nas práticas. Não nos referimos aos próprios autores, mas ao modo como eles são evocados para dar subsídios às modalidades de prática relatadas.

Essa dimensão tornou-se visivel por termos identificado que, fundamentalmente, todos os trabalhos fazem referência a um grupo aparentemente reduzido de autores. Entretanto, visto que identificamos diferenças entre as ações evidenciadas nas práticas desses trabalhos, iniciamos essa investigação.

0 artigo 12 foi um trabalho que nos serviu de referência do modelo de prática pedagógica pautado na ação estratégica. Foi selecionado por ter forte embasamento teórico e conceitual. Nele, as referências aos trabalhos de Carr e Kemmis foram importantes. Transcrevemos, a seguir, um exemplo dessa relação:

Com base nas reflexões, planeja-se uma nova ação; porém, mesmo sendo ela controlada pelo planejamento, não há total controle do que vai acontecer, uma vez que os juizos práticos dos participantes podem estar equivocados e os resultados podem ser outros que não os esperados. "A mudança das práticas educativas, dos entendimentos e das situações depende de uma espiral de ciclos em que a ação estará submetida a um controle programático" (CARR; KEMMIS, 1988, p. 196). (12)

Ao descrever as tecnologias de ensino, Popkewitz (2001, p. 88) afirma que

as tecnologias atribuídas ao ensino não são simplesmente procedimentos para guiar a ação. 0 aparato conceitual que organiza as tecnologias do ensino é, em certo 
sentido, um conhecimento instrumental, procedimental, sobre a maneira como os professores organizam a classe. A literatura oculta no currículo das últimas décadas, baseada na escola Alemã de Frankfurt, tem dado muita atenção a esse raciocínio instrumental (ver por exemplo Carr e Kemmis).

Por meio desses exemplos, notamos uma simetria entre os modelos estratégicos de prática como elaborados pelos autores do trabalho codificado (12) e a literatura, ressaltando a importância dessa concepção para o campo. Além disso, pudemos evidenciar a referência estratégica em trabalhos que se remetem diretamente aos autores Antônio Nóvoa, Schön e Maldaner. Transcrevemos, a seguir, alguns trechos com essa referência:

[...] pois como alertou Nóvoa (1995, p.31) "toda formação encerra um projeto de ação. E de trans-formação. E não há projetos sem opções”. (22)

O "saber fazer" deve levar o professor a "manter-se em contato com o que as crianças realmente estão dizendo ou fazendo" com o intuito de ajudá-las a entender o que está acontecendo e ligar o seu conhecimento escolar ao seu conhecimento cotidiano (Schön, 1992). (20)

Assim, os objetos de estudo poderão ser as teorias didáticas pessoais, seja dos professores, seja dos alunos, implicando no questionamento das visões de ciência, de educação e de suas finalidades, de conteúdos, de metodologias e modos de avaliação, entre outros. Isto poderá ajudar os futuros professores não só a avançarem em seus conhecimentos e práticas, mas igualmente no seu entendimento epistemológico de como estes se constituem, superando visões simplistas que frequentemente trazem (Maldaner, 1999). (18)
A maior parte dos trabalhos que tem como referencial teórico Lee Shulman, Zeichner e os autores dos conceitos de comunidade de prática, Jean Lave e Etiene Wenger, fazem referência a modelos normativos de ação ao conceituar as práticas pedagógicas:

Mediante análise dos dados expressos pelas professoras nas entrevistas realizadas, assim como daqueles obtidos nos processos de elaboração, implementação e análise de suas aulas, apontamos quais foram as principais fontes ou experiências, acerca da profissão, vividas pelas docentes, como elas influenciaram as participantes durante o processo, além, é claro, dos principais conhecimentos expressos pelos participantes, dentre os apontados na "base de conhecimentos para o ensino" de Shulman. (14)

Segundo Tardif (2002), os professores produzem ou tentam produzir, em seus contextos de trabalho, saberes que eles compreendem e dominam, saberes da experiência, que, segundo Lima e Reali(2002), tendem a se converter em habitus, rotinas, ou "saberes tácitos", segundo Zeichner (1993, 437). (14)

[...] importância deste diálogo com pares e formadores, trazida pelos atendimentos em grupo, não é surpreendente se partimos da perspectiva de que a aprendizagem deve ser entendida como participação em uma comunidade (LAVE; WENGER, 1991). (13)

Nos trabalhos de referencial ligado a abordagens psicanalíticas, pudemos perceber uma ênfase na construção da identidade docente a partir de processos da prática:

[...] deve ser deixado espaço para que o saber pessoal do aprendiz seja colocado em jogo e moldado segundo seus próprios ritmos e critérios. Em nossa interpretação 
privilegiamos dois elementos como reguladores do processo de formação docente: o outro (a referência inconsciente) e o gozo (a satisfação inconsciente, FINK, 1998). Neste processo, por um lado, se o formador for colocado na posição de outro pelo formando, via transferência pedagógica, terá a possibilidade efetiva de influenciá-lo e de atingir seu saber pessoal; por outro lado, o formando poderá sustentar-se no processo de maneira estável, somente deslocando para o novo saber parte de sua satisfação inconsciente anteriormente alocada em outros saberes e/ou circuitos inerciais. (28)

E em artigos que enfatizam as questões de linguagem e discurso, fica evidente a compreensão da prática pedagógica como ação comunicativa:

É concepção de Vygotsky (2000) e de outros pesquisadores da abordagem histórico-cultural, que a aprendizagem e a reconstrução cultural só ocorrem nas interações sociais. (21)

Foi visível, também, o quanto diversos artigos citaram trechos de trabalhos de Philippe Perrenoud diretamente relacionados às práticas pedagógicas. As citações fundamentam visões sobre essas práticas como ações de natureza estratégica (trecho do artigo 22), normativa (trecho do artigo 1) e dramatúrgica (trecho do artigo 8). Transcrevemos, a seguir, excertos que exemplificam essa dinâmica:

Como Perrenoud (1993), consideramos que é necessário fazer com que os futuros professores passem por circunstâncias de improvisação (próprias à ação didática) regularmente durante seus estudos e analisem o que pensaram, sentiram e fizeram, para que possam dominar pouco a pouco seus impulsos, emoções excessivas, hostilidade face a certas atitudes dos alunos e indiferença perante alguns sinais. (22)
De fato, a passagem de um trabalho compartimentado - com funções pouco precisas e relações de autoridade aleatórias - para modalidades de trabalho mais colaborativas - caracterizadas pelo exercicio coletivo de elaboração, transformação, análise e avaliação - é somente possivel mediante a mobilização de vários saberes (PERRENOUD, 2000). (1)

Esse vinculo educativo, estabelecido entre E.K. e seus alunos, mobiliza vários aspectos da personalidade do professor, revelando a complexidade de sentimentos que estão envolvidos na relação pedagógica. Como Perrenoud (2000) nos aponta: "O vínculo educativo é muito complexo, pois mobiliza demasiadas camadas de sua personalidade para que o professor domine racionalmente o todo da relação que constrói com seus alunos. [...] A primeira competência do professor é aceitar essa complexidade, reconhecer os implícitos do ofício, as zonas de sombra, a dificuldade de saber exatamente em que motivos e em que história pessoal se ancora seu desejo de ensinar" (Perrenoud, 2000:151). (8)

\section{Entre contextos e ações}

Outra dimensão que a utilização de categorias de ação evidenciou em nossas análises das práticas pedagógicas foi o foco mais ou menos local dado a essas práticas. Esse distanciamento ou aproximação focal pode ser elaborado em sua relação com a dimensão atribuída à prática pedagógica e ao contexto elaborado pela própria pesquisa.

Utilizamos o conceito de contexto tal como proposto por David Bloome e colaboradores (2008). Esses autores discutem que microcontextos (aspectos mais locais da sala de aula, como as histórias individuais e relações pessoais entre os membros) e macrocontextos (aspectos mais amplos, como questões sociais, étnicas e de gênero) estão presentes, de forma 
simultânea, temporal e espacialmente. Cabe ao pesquisador identificar os tipos de contexto que permeiam suas observações e reconhecer a limitação de explorar todos os contextos que influenciam uma sala de aula ou outro espaço de formação. Cabe também ao pesquisador identificar os contextos nos quais ele mesmo está imerso, seus referenciais e pontos de vista e indagar como esses contextos da própria pesquisa constituem-se em estruturas que determinam o olhar para seu objeto. Procuramos, portanto, encontrar nesse referencial padrões de associação entre os contextos selecionados pelos pesquisadores para explorar as práticas pedagógicas e relacioná-los aos modelos de ação que fundamentam essas práticas.

Além dos contextos explicitados pelas pesquisas, identificamos as dimensões relacionadas às práticas pedagógicas elaboradas pelos estudos. De acordo com os sujeitos, a metodologia e a forma de apresentação dos resultados utilizados nos textos, classificamos o foco das pesquisas em: i) um indivíduo; ii) um grupo; ou iii) um aspecto geral de formação de professores, tal como um documento, uma instituição ou uma política pública. 0 gráfico 1 relaciona as categorias de ação com as dimensões das práticas pedagógicas elaboradas pelos trabalhos analisados.

Gráfico 1 - Distribuição de ocorrências de citações dentro das diferentes categorias de ação nos artigos analisados e dimensões enfatizadas

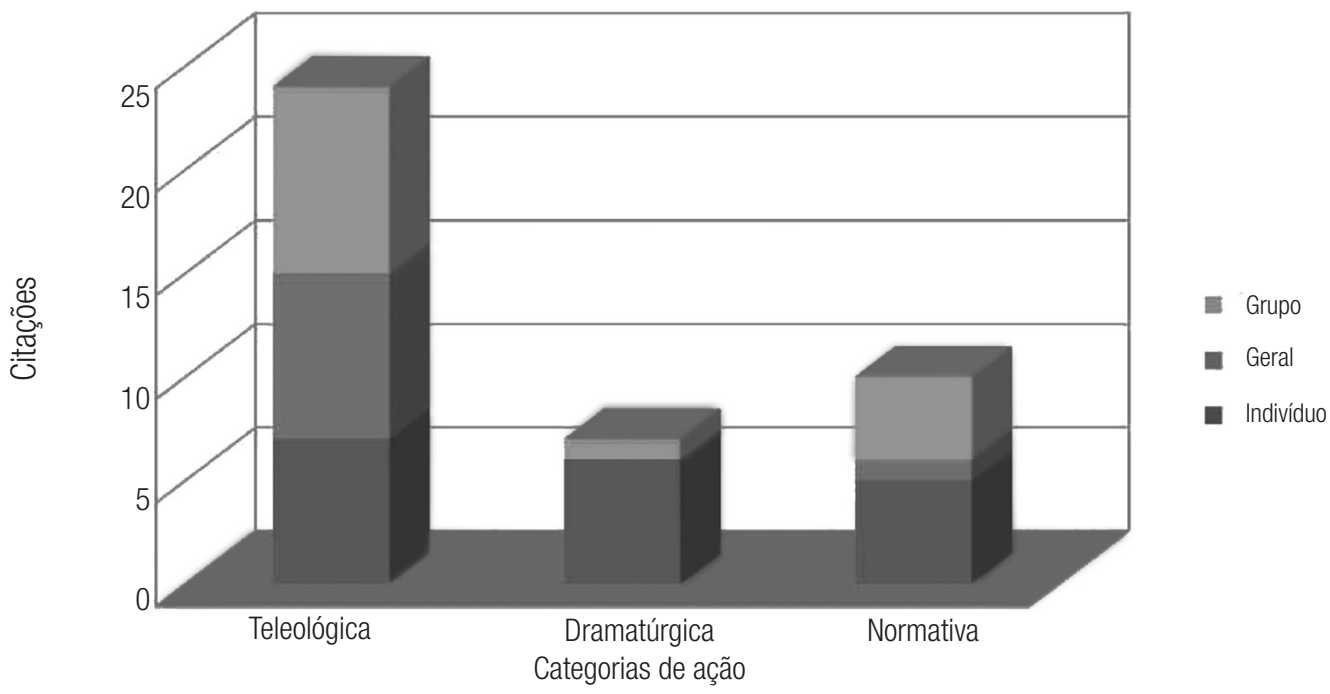

Fonte: dados da pesquisa.

Por meio dessa análise, pudemos reforçar que há uma plasticidade nas concepções de prática pedagógica e que os modelos de ação permitem que sejam evidenciados alguns aspectos interessantes para compreendê-las. As ações estratégicas, as mais prevalentes nos trabalhos analisados, foram observadas em pesquisas que tinham o foco tanto na dimensão individual quanto em aspectos mais gerais ou de grupos. Foi possível identificar, ainda, que as práticas como ações estratégicas relacionam-se, prioritariamente, ao contexto da sala de aula, um espaço onde estão em jogo dimensões da individualidade e do papel social do fazer docente. A estratégia normalmente refere-se ao contexto local, à melhoria do processo de aprendizagem dos alunos imediatamente localizados no local e no tempo da sala de aula. Além disso, as pesquisas elaboram também a sala de aula em seus contextos sociais, culturais, institucionais, ou seja, em dimensões gerais, macrocontextuais. 
Outro aspecto bastante relevante em nossas análises foi que, quando as pesquisas trataram da prática pedagógica como ação normativa, foram enfatizadas as questões de profissionalização, de um posicionamento crítico do professor, ou seja, um deslocamento analítico para aspectos macrocontextuais. Esperávamos que o conjunto metodológico trataria, então, de análises de grandes grupos e/ou instituições, ou seja, de dimensões gerais. Entretanto, nossos resultados indicam que as ações normativas foram citadas em pesquisas que focam dimensões locais, com ênfase na análise das aprendizagens em pequenos grupos e em percursos individuais, discutindo-as com base macrocontextual. Já as práticas pedagógicas como ações dramatúrgicas elaboradas pelas pesquisas analisadas estão bastante vinculadas às dimensões individuais e suas relações com o fazer docente. As práticas são vistas como elaborações sensíveis a partir das relações cara a cara, no cotidiano da docência. Nesse aspecto, embora os contextos macro sejam tratados por esses textos, a ênfase de discussão recai em aspectos de caráter microcontextual.

Pudemos identificar, de modo geral, que as pesquisas têm se dedicado a análises macrocontextuais, enquanto o foco dessas pesquisas está, normalmente, em grupos pequenos. Para Bloome et al. (2008, p. 30-31):

0 contexto não é um local de variáveis independentes que influenciam um evento, mas um local de relações construídas socialmente entre um e outros eventos, entre pessoas em um lugar e pessoas em outros lugares, entre uma instituição social e outras instituições sociais, entre um tempo e outros tempos e assim por diante. E essas relações são motivadas, ou seja, elas são muito mais sobre a construção de significados, relações de poder, identidades e relações sociais do que são reflexos de si mesmos.

Muitos dos sentidos de prática pedagógica elaborados nos trabalhos analisados, portanto, têm relacionado os microcontextos - fundamentalmente nas ações dramatúrgicas de nível individual e de grupo - com os macrocontextos sociais que permeiam a profissionalização e as instituições de formação de professores. Porém, é no modelo das ações comunicativas que os contextos se tornam mais relacionados e que a prática pedagógica, durante a formação de professores, ganha sentidos mais complexos.

\section{Ação comunicativa como devir}

A quarta ação conceituada por Habermas, a ação comunicativa, aparece nos textos analisados como devir ou como projeto ideal a ser alcançado. Nesse sentido, a ação comunicativa assume um caráter de utopia. Verificamos uma grande referência, na literatura analisada, à busca por uma efetiva comunicação entre a escola e a universidade e seus atores durante as práticas educativas. 0 campo de formação de professores de ciências assume, de forma bastante recorrente, que há um ideal de formação do professor em ações comunicativas nas quais os atores construam um consenso sobre o que é ser professor e em que estejam contempladas: as esferas estratégicas ligadas ao conteúdo, à objetividade da tarefa educativa, às atividades técnicas etc; as esferas mais ligadas à subjetividade do tornar-se professor, compreender-se e ser reconhecido como tal nas ações dramatúrgicas; as esferas normativas, que compreendem características do campo da profissionalização, assumindo sua função social, os discursos ideológicos da docência, as regras e os procedimentos que caracterizam essa comunidade profissional. Esse devir pode ser ilustrado a partir de um trecho do artigo 28:

Certamente, o problema mais difícil será articular essa triangulação de forma que professores, licenciandos e docentes universitários experimentem um vínculo grupal, gerador de um novo tipo de satisfação e capaz de modificar suas rotinas e estabilizar sua colaboração. Parece-nos 
que a institucionalização dessa prática, para poder se sustentar durante os impasses, improvisações e "pequenos incêndios" que acontecem em qualquer processo inovador, deverá ser ancorada numa dinâmica grupal com utopias e pactos partilhados pelos participantes, ou seja, num projeto efetivamente comum. (28)

$\mathrm{Na}$ ação comunicativa, há uma superposição dos mundos, uma mescla que os torna indistinguíveis. Assim como apontam Bloome e seus colaboradores, os contextos se sobrepõem, macro e microcontextos participam da composição dos sentidos de prática pedagógica. A escola, local das atividades docentes, reconfigura-se em uma rede de muitas relações de identidade, normas, objetos. A ação comunicativa relaciona-se com essa compreensão de que tanto o mundo material objetivo quanto o mundo das vontades, das identidades e das normas sociais se superpõem na construção das ações das práticas de formação de professores.

\section{Considerações finais}

No contexto nacional, as pesquisas sobre formação de professores de ciências têm sido desenvolvidas, em grande parte, por docentes universitários que atuam como formadores de professores de ciências nas atividades de orientação de estágios e nas disciplinas ligadas à prática pedagógica. Identificar tendências da pesquisa no campo é também identificar tendências nas ações de formação. Sobre esse tipo de pesquisa, Bloome et al. (2008, p. 40) afirmam que:

não há nelas menos história, cultura, política e ideologia, e elas não envolvem menos questões de poder [...] pesquisadores devem estar reflexivamente a par dos contextos de suas pesquisas e levá-los em consideração.

Ao propormos uma categorização de ação para analisar as práticas pedagógicas constituídas pelas pesquisas sobre formação de professores de ciências, temos por objetivo construir uma ferramenta fundamentada na teoria social para analisar a produção do campo. Paralelamente, buscamos orientar nossas análises a partir de uma perspectiva sóciohistórica centrada na linguagem, que constitui relações de poder com caráter polifônico e polissêmico. Assim, propomos que os textos de pesquisa sejam interpretados como uma linguagem que se origina e se orienta para uma comunidade, constrói materialidade e contextos e é coletiva. 0 texto, portanto, não é neutro. Ele constitui o próprio campo e participa das construções que permeiam esse campo.

Ao analisar os textos, identificamos que as práticas pedagógicas como ações não têm caráter monolítico, não respondem de forma homogênea a modelos ou paradigmas de formação específicos, nem a saberes originados de contextos puros. Ao interpretar as práticas pedagógicas como ações, é possível identificar o caráter multifacetado das práticas formativas. Há uma coexistência de perspectivas de ação distintas, evidenciando-se o caráter híbrido e complexo dessas ações. É a complexidade dessas ações pedagógicas - originadas na polifonia dos discursos de formação de professores, discursos que emergem de contextos igualmente complexos - que proporciona aos atores envolvidos na formação de professores a possibilidade de produzir significados divergentes de um dado discurso hegemônico. Assim, ações também evidenciam o caráter da produção fundamentado no fazer cotidiano dos atores. Construir categorizações como a que propomos é buscar uma exploração da identidade social da pesquisa, em um movimento que supera as denominações de identidade social macrocontextuais previamente dadas para a identificação de processos de interação face a face, cotidianos (BLO0ME et al., 2005).

Assim, as ações representam uma categorização que evidencia a complexidade cotidiana das relações estabelecidas entre a universidade e a escola nas atividades de prática pedagógica da formação de professores. 


\section{Referências}

ANDRÉ, Marli Eliza Dalmazo Afonso de et al. Estado da arte da formação de professores no Brasil. Educação e Sociedade, v. 68, p. 301-309, 1999.

BAZERMAN, Charles; PRIOR, Paul A. What writing does and how it does it: an introduction to analyzing texts and textual practices. Mahwah: Lawrence Erlbaum Associates, 2004.

BAZERMAN, Charles; PRIOR, Paul A. Participating in emergent socio-literate worlds: genre, disciplinarity, interdisciplinarity. In: BEACH, Richard et al. (Eds.). Multidisciplinary perspectives on literacy research. 2. ed. Cresskill: Hampton, 2005.

BEJARANO, Nelson Rui Ribas; CARVALHO, Ana Maria Pessoa de. Tornando-se professor de ciências: crenças e conflitos. Ciência \& Educação, v. 9, n. 1, p. 1-15, 2003

BERZEZINSKI, Iria. Formação de profissionais da educação (1997-2002). Brasília: MEC, Inep ANPEd, 2006.

BLOOME, David et al. Discourse analysis \& the study of classroom language \& literacy events: a microethnographic perspective. Mahwah: L. Erlbaum Associates, 2005.

BLOOME, David et al. On discourse analysis in classrooms: approaches to language and literacy research. New York: Teachers College Press: NCRLL/National Conference on Research in Language and Literacy, 2008.

CALDAS, Andréa do Rocio. Desistência e resistência no trabalho docente: um estudo das professoras e professores do ensino fundamental da rede municipal de educação de Curitiba. Tese (Doutorado) - Universidade Federal do Paraná, Curitiba, 2007.

CARVALHO, Anna Maria P. A influência das mudanças da legislação na formaç̧ão dos professores: as 300 horas de estágio supervisionado. Ciência \& Educação, v. 7, n. 1, p. 113-122, 2001.

CASARIEGO, Florence M.; LUCAS, Mariana C.; FERREIRA, Marcia S. Panorama da produção acadêmica sobre formação de professores de ciências (2000-2010): uma análise em periódicos nacionais. In: ENCONTRO NACIONAL DE PESQUISA EM EDUCAÇÃO EM CIÊNCIAS \& CONGRESO IBEROAMERICANO DE INVESTIGACIÒN DE ENZEÑANZA DE LAS CIENCIAS, 8., 2011. Atas..., 2011. p. 1-12.

DINIZ-PEREIRA, Julio Emílio. Paradigmas contemporâneos da formação docente. In: SOUZA, João Valdir (Org.). Formação de professores para a educação básica: dez anos de LDB. 1. ed. Belo Horizonte: Autêntica, 2007. p. 253-264.

ECHEVERRÍA, Augustina Rosa; BELISÁRIO, Celso Martins. Formação inicial e continuada de professores num núcleo de pesquisa em ensino de ciências. Revista Brasileira de Pesquisa em Educação em Ciências, v. 8, n. 3, 2008.

FEITOSA, Raphael Alves; LEITE, Raquel Crossara Maia; FREITAS, Ana Lucia Ponte. Projeto aprendiz: interação universidade-escola para realização de atividades experimentais no ensino médio. Ciência \& Educação, v. 17, n. 2, p. 301-320, 2011.

FRANCO, Creso et al. Qualidade e eqüidade em educação: reconsiderando o significado de "fatores intra-escolares". Ensaio: Avaliação e Políticas Públicas em Educação, v. 15, n. 55, jun. 2007.

FREITAS, Maria Teeresa de Assunção. A abordagem sócio-histórica como orientadora da pesquisa qualitativa. Cadernos de Pesquisa, v. 116, p. 21-39, 2002.

GATTI, Bernadete Angelina. A construção da pesquisa em educação no Brasil. Brasília: Plano, 2002.

HABERMAS, Jürgen. Reason and the rationalization of society. Boston: Beacon Press, 1984.

NUNES, Célia Maria Fernandes. Saberes docentes e formação de professores: um breve panorama da pesquisa brasileira. Educação e Sociedade, v. 74, p. 27-42, 2001. 
POPKEWITZ, Thomas S. Lutando em desefa da alma: a política do ensino e a construção do professor. Porto Alegre: Artmed, 2001.

ROCHA, Maria Silvia Pinto de Moura Librand; PEROSA, Graziela Serroni. Notas etnográficas sobre a desigualdade educacional brasileira. Educação \& Sociedade, v. 29, n. 103, p. 425-449, ago. 2008.

ROSA, Maria Inês Freitas Petrucci; MEDEIROS, Abrahão Gomes; SHIMABUKURO, Eunica Kimie Higa. Tutoria na formação de professores de ciências: um modelo pautado na racionalidade prática. Revista Brasileira de Pesquisa em Educação em Ciências, v. 1, n. 3, p. 28-39, 2001.

ROSA, Maria Inês Freitas Petrucci et al. Formação de professores da área de ciências sob a perspectiva da investigação-ação. Revista Brasileira de Pesquisa em Educação em Ciências, v. 3, n. 1, p. 5-14, 2003.

SANTOS, Lucíola Licínio. Paradigmas que orientam a formação docente. In: SOUZA, João Valdir Alves (Org.). Formação de professores para a educação básica: dez anos da LDB. Belo Horizonte: Autêntica, 2007. p. 235-252.

SCHÖN, Donald. El profesional reflexivo: cómo piensan los profesionales cuando actúan. Barcelona: Paidós, 1998.

SZTAJN, Paola; BONAMINO, Alicia; FRANCO, Creso. Formação docente nos surveys de avaliação educacional. Cadernos de Pesquisa, n. 118, p. 11-39, mar. 2003.

TARDIF, Maurice. Saberes docentes e formação profissional. 6. ed. Petrópolis: Vozes, 2006.

TERRIEN, Jacques. Saber da experiência e competência profissional: como os docentes produzem sua profissão. Contexto e Educação, v. 12, n. 48, p. 7-36, 1997.

WERTSCH, James V. Voices of the mind: a sociocultural approach to mediated action. Cambridge: Harvard University Press, 1993.

ZEICHNER, Ken. Improving teacher education in the United States. New Orleans, 2011. Disponivel em: <http://www.aera.net/ AnnualMeetingsOtherEvents/PreviousAnnualMeetings/2011AnnualMeeting/tabid/11257/Default.aspx>. Acesso em: 25 out. 2012.

\section{Trabalhos analisados}

BAPTISTA, Geilsa Costa Santos. A importância da reflexão sobre a prática de ensino para a formação docente inicial em ciências biológicas. Ensaio: Pesquisa em Educação em Ciências, v. 5, n. 2, p. 4-12, 2003.

BARCELOS, Nora Ney Santos; VILLANI, Alberto. Troca entre universidade e escola na formação docente: uma experiência de formação inicial e continuada. Ciência \& Educação, v. 12, n. 1, p. 73-97, 2006.

BAROLLI, Elisabeth et al. A crônica da disciplina: uma experiência na formação de professores de ciências. Revista Brasileira de Pesquisa em Educação em Ciências, v. 1, n. 2, 2001.

BEJARANO, Nelson Rui Ribas; CARVALHO, Ana Maria Pessoa de. Tornando-se professor de ciências: crenças e conflitos. Ciência \& Educação, v. 9, n. 1, p. 1-15, 2003.

CAMARGO, Sérgio; NARDI, Roberto. Formação de professores de física: os estágios supervisionados como fonte de pesquisa sobre a prática de ensino. Revista Brasileira de Pesquisa em Educação em Ciências, v. 3, n. 3, p. 34-55, 2003.

CHUDO, Marisa Laporta; SONZOGNO, Maria Cecília. 0 processo de ensino-aprendizagem de adultos universitários: um caso da biologia educacional na formação de educadores. Investigações em Ensino de Ciências, v. 12, n. 2, p. 183-203, 2007.

DINIZ, Renato Eugênio da Silva; CAMPOS, Luciana Maria Lunardi. Formação inicial reflexiva de professores de ciências e biologia: possibilidades e limites de uma proposta. Revista Brasileira de Pesquisa em Educação em Ciências, v. 4, n. 2, p. 27-39, 2004.

ECHEVERRÍA, Augustina Rosa; BELISÁRIO, Celso Martins. Formação inicial e continuada de professores num núcleo de pesquisa em ensino de ciências. Revista Brasileira de Pesquisa em Educação em Ciências, v. 8, n. 3, 2008. 
FERREIRA, Doralice Bortoloci; VILLANI, Alberto. Uma reflexão sobre prática e ações na formação de professores para o ensino de física. Revista Brasileira de Pesquisa em Educação em Ciências, v. 2, n. 2, p. 63-76, 2002.

FREITAS, Denise de; VILLANI, Alberto. Formação de professores de ciências: um desafio sem limites. Investigações em Ensino de Ciências, v. 7, n. 3, p. 215-230, 2002.

GALIAZZI, Maria do Carmo; MORAES, Roque. Educação pela pesquisa como modo, tempo e espaço de qualificação da formação de professores de ciências. Ciência \& Educação, v. 8, n. 2, p. 237-252, 2002.

GIL-PEREZ, Daniel et al. A educação científica e a situação do mundo: um programa de atividades dirigido a professores. Ciência \& Educação, v. 9, n. 1, p. 123-146, 2003.

LINHARES, Marília Paixão; REIS, Ernesto Macedo. Estudos de caso como estratégia de ensino na formação de professores de física. Ciência \& Educação, v. 14, n. 3, p. 555-574, 2008.

LONGHINI, Marcos Daniel. 0 conhecimento do conteúdo científico e a formação do professor das séries iniciais do ensino fundamental. Investigações em Ensino de Ciências, v. 13, n. 2, p. 241-253, 2008.

LONGHINI, Marcos Daniel; HARTWIG, Dário Rodney. A interação entre os conhecimentos de um professor atuante e de um aspirante como subsídio para a aprendizagem da docência. Ciência \& Educação, v. 13, n. 3, p. 435-451, 2007.

MENDES, Regina; MUNFORD, Danusa. Dialogando saberes - pesquisa e prática de ensino na formação de professores de ciências e biologia. Ensaio: Pesquisa em Educação em Ciências, v. 7, n. 3, p. 1-18, 2005.

MION, Rejane Aurora; ANGOTTI, José André Peres. Em busca de um perfil epistemológico para a prática educacional em educação em ciências. Ciência \& Educação, v. 11, n. 2, p. 165-180, 2005.

PIERSON, Alice H. C.; NEVES, Marcos Rogério. Interdisciplinaridade na formação de professores de ciências: conhecendo obstáculos. Revista Brasileira de Pesquisa em Educação em Ciências, v. 1, n. 2, p. 120-131, 2001.

PIETROCOLA, Mauricio; ALVES FILHO, José de Pinho; PINHEIRO, Terezinha de Fátima. Prática interdisciplinar na formação disciplinar de professores de ciências. Investigações em Ensino de Ciências, v. 8, n. 2, p. 131-152, 2003.

QUEIROZ, Glória Regina Pessôa Campello; BARBOSA-LIMA, Maria da Conceição Almeida. Conhecimento científico, seu ensino e aprendizagem: atualidade do construtivismo. Ciência \& Educação, v. 13, n. 3, p. 273-291, 2007.

REIS, Ernesto Macedo; LINHARES, Marília Paixão. Integrando o espaço virtual de aprendizagem "Eva" à formação de professores: estudo de caso sobre o currículo de física no ensino médio. Ensaio: Pesquisa em Educação em Ciências, v. 10, n. 2, 2008.

ROSA, Maria Inês Freitas Petrucci et al. Formação de professores da área de ciências sob a perspectiva da investigação-ação. Revista Brasileira de Pesquisa em Educação em Ciências, v. 3, n. 1, p. 5-14, 2003.

ROSA, Maria Inês Freitas Petrucci; MEDEIROS, Abrahão Gomes; SHIMABUKURO, Eunica Kimie Higa. Tutoria na formação de professores de ciências - um modelo pautado na racionalidade prática. Revista Brasileira de Pesquisa em Educação em Ciências, v. 1, n. 3, p. 28-39, 2001.

SANTOS, Wildson Luiz Pereira dos et al. Formação de professores: uma proposta de pesquisa a partir da reflexão sobre a prática docente. Ensaio: Pesquisa em Educação em Ciências, v. 8, n. 1, p. 1-14, 2006.

SILVA, Maria Helena Santos; DUARTE, Maria da Conceição. 0 diário de aula na formação de professores reflexivos:resultados de uma experiência com professores estagiários de biologia/geologia. Revista Brasileira de Educação em Ciências, v. 1, n. 2, 2001

SILVEIRA, Felipa Pacifico Ribeiro de Assis. A aprendizagem significativa na formação de professores de biologia: 0 uso de mapas conceituais. Revista Brasileira de Pesquisa em Educação em Ciências, v. 4, n. 3, 2004.

TEIXEIRA, Lia Cardoso Rocha Saraiva; OLIVEIRA, Ana Mourão. A relação teoria-prática na formação do educador e seu significado para a prática pedagógica do professor de biologia. Ensaio: Pesquisa em Educação em Ciências, v. 7, n. especial, p. 1-23, 2005. 
TEIXEIRA, Paulo. Iniciação à pesquisa: um eixo de articulação no processo formativo de professores de ciências biológicas. Ensaio: Pesquisa em Educação em Ciências, v. 5, n. 1, 2003.

VILLANI, Alberto; FRANZONI, Marisa. A competência dialógica e a formação de um grupo "docente". Investigações em Ensino de Ciências, v. 5, n. 3, p. 191-211, 2000.

VILLANI, Alberto; FRANZONI, Marisa; VALADARES, Juarez M. Desenvolvimento de um grupo de licenciandos numa disciplina de prática de ensino de física e biologia. Investigações em Ensino de Ciências, v. 13, n. 2, p. 143-168, 2008.

Recebido em: 15.01 .13

Aprovado em: 27.06 .2013

Priscila Correia Fernandes possui licenciatura em Ciências Biológicas pela Universidade Estadual de Campinas (Unicamp, 2001) e doutorado em Biologia Funcional e Molecular pela mesma universidade (2005). Desenvolveu pós-doutorado na Faculdade de Educação da Universidade Federal de Minas Gerais (UFMG), junto ao grupo de pesquisa Linguagem e Cognição no ano de 2012. É professora da Universidade Federal de São João del-Rei (UFSJ), lotada no Departamento de Ciências Naturais. Atua principalmente no curso de licenciatura em Ciências Biológicas, em disciplinas ligadas à formação docente. Tem experiência na área de ensino de ciências e biologia e atualmente desenvolve pesquisa de fundamentação sóciohistórica sobre formação de professores.

Danusa Munford possui licenciatura e bacharelado em Ciências Biológicas pela Universidade de São Paulo (USP), mestrado em Biologia Genética pela mesma universidade, doutorado em Educação (em Curriculum and Instruction) na Pennsylvania State University (2002) e pós-doutorado na Ohio State University (em Teaching and Learning). Atualmente, é professora associada da Faculdade de Educação da Universidade Federal de Minas Gerais (UFMG). Tem experiência na área de educação, com ênfase em formação de professores, atuando principalmente nos seguintes temas: ensino-aprendizagem de ciências nos anos iniciais e argumentação.

Marcia Serra Ferreira possui licenciatura em Ciências Biológicas pela Universidade Federal do Rio de Janeiro (UFRJ, 1988), bacharelado em Ecologia (1989), mestrado em Educação pela Pontifícia Universidade Católica do Rio de Janeiro (PUC-RJ, 1995) e doutorado em Educação pela UFRJ (2005). É professora adjunta da Faculdade de Educação da UFRJ, atuando como Superintendente Acadêmica de Pós-Graduação da Pró-Reitoria de Pós-Graduação e Pesquisa (PR2). Leciona na graduação em Ciências Biológicas e no Programa de Pós-Graduação em Educação da instituição. Tem experiência na área de educação, com ênfase em currículo, atuando principalmente nos seguintes temas: ensino de ciências, história do currículo e das disciplinas, formação de professores e conhecimentos escolares em ciências. É pesquisadora do CNPq (PQ2) e Jovem Cientista do Estado do Rio de Janeiro (JCNE/FAPERJ). 